\title{
Primary Carcinoids of the Liver: A Review of Symptoms, Diagnosis and Treatments
}

\author{
Gianpiero Gravante $^{\mathrm{a}}$ Nicola De Liguori Carino ${ }^{c}$ John Overton ${ }^{b}$ \\ Tommaso Maria Manzia ${ }^{d}$ Giuseppe Orlando ${ }^{e}$ \\ ${ }^{a}$ Department of Colorectal Surgery, Whipps Cross University Hospital, ${ }^{\text {b } B a r t s ~ a n d ~ t h e ~ L o n d o n ~ S c h o o l ~ o f ~ M e d i c i n e ~}$ \\ and Dentistry, London, 'CHepato-Pancreato-Biliary Unit and Transplant Unit, St James's University Hospital, Leeds, \\ and ${ }^{\mathrm{d}}$ Department Hepatobiliary and Pancreatic Surgery, Queen Elizabeth Hospital, Birmingham, UK; \\ eTransplant Unit, San Salvatore Hospital, University of L'Aquila, L'Aquila, Italy
}

\section{Key Words}

Primary carcinoids • Liver neoplasms • Endocrine liver tumours

\begin{abstract}
Introduction: To elucidate the clinical presentation, diagnosis and management of primary hepatic carcinoid tumours, a literature search was conducted and summarized. Materials and Methods: Published primary hepatic carcinoid tumour case reports and series were searched and selected in the Medline, EMBASE and Cochrane Library databases. $\boldsymbol{R} \boldsymbol{e}$ sults: Sixty-nine cases meeting the inclusion criteria were identified. Twenty-eight patients were male (28/69=40.6\%). The median age at diagnosis was 50 years (range $8-83$ years). The most common presentation described was abdominal pain $(23 / 69=33.3 \%)$, or no symptoms at all $(16 / 69=23.2 \%)$. Symptoms of carcinoid syndrome were described in $18.9 \%$ of cases (13/69). The most frequently secreted hormones were gastrin $(7 / 69=10.1 \%)$ and chromogranin A. In $31.9 \%$ of patients (22/69), surgical treatment was not adopted. Of those treated surgically, $63.8 \%$ underwent a hepatic resection (44/69) and $4.3 \%$ a liver transplantation (3/69). After a median follow-up of 31 months (range 0-180 months), 39.1\% of patients (27/69) died and 52.2\% (36/69) survived. Conclusions: Primary hepatic carcinoids are an important entity in which the exclusion of different primary locations is neces-
\end{abstract}

sary. When feasible, hepatic resection is the treatment of choice. Liver transplantation has been described in a small number of unresectable cases.

Copyright $\odot 2008$ S. Karger AG, Basel

\section{Introduction}

Carcinoid tumours are slow-growing neoplasms derived from the neuroendocrine system. A large number of them arise within the gastrointestinal tract [1], mostly in the appendix and the terminal ileum $[1,2]$, while a small proportion develop within other organs (for example bronchi). The liver is a common site for metastases from carcinoids originating in the gastrointestinal tract, but may also harbour primary carcinoids.

Primary hepatic carcinoid tumours (PHCT) are even rarer malignancies than carcinoids that have metastasised to the liver [3]. Recently, work has been conducted to compile published case reports of PHCT in order to obtain an insight into the symptoms, diagnosis, treatment and prognosis of this disease [4-6]. Most patients are asymptomatic, but some present with the carcinoid syndrome [4]. Surgical resection, when feasible, is the preferred treatment ( $85 \%$ of cases), and achieves 5 -year survival rates of $80-92.5 \%[4,6]$. However, recurrences are still very common, which would suggest that patient

\section{KARGER}

Fax +4161306 1234 E-Mail karger@karger.ch www.karger.com
Gianpiero Gravante

Department of Colorectal Surgery

Whipps Cross University Hospital

London E11 1NR (UK)

Tel. +39 3486701 961, E-Mail ggravante@hotmail.com 
follow-up of longer than 5 years would be more appropriate [4].

In this review, we have summarized the results of a literature search into all reported cases of PHCT, with the view to gain further information relating to the clinical presentation, diagnosis and management of this rare disease.

\section{Materials and Methods}

A literature search was undertaken for all published studies focusing on PHCT, including both case reports and patient series. Articles were selected from the Medline, EMBASE and Cochrane Central Register of Controlled Trials (CENTRAL) databases using the following key words for the search: carcinoid* ${ }^{*}$ liver, tumour, primary and hepatic. Potentially relevant studies were identified by the title and the abstract; then, the complete articles were assessed in detail. The patient's clinical data were extracted from the articles and inserted into a specifically designed Excel spreadsheet including demographic and clinical details of patients, type of treatment received, follow-up and survival. Data collection was carried out independently by two researchers (G.G. and C.N.D.L.).

\section{Statistical Analysis}

Data analysis was performed using the Statistical Package for the Social Sciences for Windows v13.0 (SPSS, Chicago, Ill., USA). Descriptive statistics for quantitative parametric variables were the mean and standard deviation (mean $\pm \mathrm{SD}$ ). Normality assumptions were demonstrated with histograms, KolmogorovSmirnov and Shapiro-Wilk testings. Descriptive statistics for qualitative variables was performed with occurrences and described with relative frequencies. Median and range (minimum and maximum) were used to describe quantitative non-parametric variables. Kaplan-Meier survival curves were calculated using data on two variables reported for all patients: the first variable, called 'Status', denoted 'censored' cases (living patients at the end of follow-up) by ' 0 ' from 'event' cases (death for the disease) by ' 1 '; the second variable was the duration of follow-up, expressed in months. The event defined on the SPSS software as 'target' was the patient's death.

\section{Results}

Sixty-nine cases meeting the inclusion criteria were identified [7-48]. Eight of them were case series, the remaining 61 were case reports. Twenty-eight patients were male (40.6\%). The median age at diagnosis was 50 years (range 8-83 years), and the highest incidence is in the fifth decade ( 23 cases), with only 5 cases under 40 years. The tumour was located in the right lobe in $49.3 \%$ of patients (34/69), the left lobe in $31.9 \%(22 / 69)$ and bilaterally in $14.5 \%$ (10/69; table 1$)$. In 55 cases, the symptoms were described in detail. Although several clinical symp-
Table 1. Tumour location

\begin{tabular}{lrr}
\hline Location & \multicolumn{2}{l}{ Patients } \\
\cline { 2 - 3 } & $\mathrm{n}$ & $\%$ \\
\hline Right lobe & $34 / 69$ & 49.3 \\
Left lobe & $22 / 69$ & 31.9 \\
Bilateral lobes & $10 / 69$ & 14.5 \\
Caudate lobe & $3 / 69$ & 4.3 \\
Omental metastases & $2 / 69$ & 2.9 \\
\hline
\end{tabular}

Table 2. Symptoms at presentation

\begin{tabular}{lcr}
\hline \multirow{2}{*}{ Symptoms } & \multicolumn{2}{l}{ Patients } \\
\cline { 2 - 3 } & $\mathrm{n}$ & $\%$ \\
\hline Abdominal pain & $23 / 69$ & 33.3 \\
No symptoms & $16 / 69$ & 23.2 \\
Diarrhea & $5 / 69$ & 7.2 \\
Jaundice & $4 / 69$ & 5.8 \\
Pulmonary failure & $4 / 69$ & 5.8 \\
Flushing & $3 / 69$ & 4.3 \\
Weight loss & $2 / 69$ & 2.9 \\
Melaena & $2 / 69$ & 2.9 \\
Liver failure & $2 / 69$ & 2.9 \\
Zollinger-Ellison syndrome & $2 / 69$ & 2.9 \\
Swelling & $2 / 69$ & 2.9 \\
Lower legs edema & $1 / 69$ & 1.4 \\
Hypoglycaemia & $1 / 69$ & 1.4 \\
Itching & $1 / 69$ & 1.4 \\
Fatigue & $1 / 69$ & 1.4 \\
Dizziness & $1 / 69$ & 1.4 \\
Cushing syndrome & $1 / 69$ & 1.4 \\
Back pain & $1 / 69$ & 1.4 \\
Anaemia & $1 / 69$ & 1.4 \\
Renal failure & $1 / 69$ & 1.4 \\
Fever & $1 / 69$ & 1.4 \\
\hline
\end{tabular}

toms were reported (table 2), the most common presentations were abdominal pain $(23 / 69 ; 33.3 \%)$, or no symptoms at all (16/69; 23.2\%). Interestingly, symptoms of carcinoid syndrome were described in only 13 cases (13/69; $18.9 \%)$, and in one case $(1 / 69 ; 1.4 \%)$ the patient did not produce any hormone. When reported, the most frequent secreted hormones were gastrin $(7 / 69 ; 10.1 \%)$ and chromogranin A (5/69; 7.2\%; table 3).

No surgical treatment was adopted for $31.9 \%$ of patients (22/69). Of those treated surgically, 44 underwent hepatic resection $(44 / 69 ; 63.8 \%)$ and 3 orthotopic liver transplantation (LT; 3/69; 4.3\%) [7-8]. The outcome was reported for 63 patients $(63 / 69 ; 91.3 \%)$ : 27 died during the 
Table 3. Secreted hormones

\begin{tabular}{lrr}
\hline Hormone & \multicolumn{2}{l}{ Patients } \\
\cline { 2 - 3 } & $\mathrm{n}$ & $\%$ \\
\hline Gastrin & $7 / 69$ & 10.1 \\
Chromogranin A & $5 / 69$ & 7.2 \\
5-HIAA & $4 / 69$ & 5.8 \\
Serotonin & $4 / 69$ & 5.8 \\
P-P & $3 / 69$ & 4.3 \\
NSE & $2 / 69$ & 2.9 \\
ACTH & $2 / 69$ & 2.9 \\
Calcitonin & $2 / 69$ & 2.9 \\
Insulin & $1 / 69$ & 1.4 \\
Met-enkephalin & $1 / 69$ & 1.4 \\
Somatostatin & $1 / 69$ & 1.4 \\
No hormone & $1 / 69$ & 1.4 \\
Not reported & $41 / 69$ & 59.4 \\
\hline
\end{tabular}

follow-up (27/69; 39.1\%), 36 survived (36/69; 52.2\%; fig. 1). In 3 patients, the length of follow-up was not specified. The median follow-up of patients was 31 months (range 0-180 months): those that survived had a median followup of 39 months (range 2-174 months), whilst the median time point of those who died was 10 months (range $0-180$ months). Three patients died within 30 days of liver resection, 4 patients were alive more than 10 years after surgery.

\section{Discussion}

PHCT are rare malignancies whose exact histological origins remain a mystery. They may originate from ectopic pancreatic or adrenal tissue found within the liver [9], or from the intrahepatic biliary epithelium where neuroendocrine cells scatter within the gallbladder and the biliary epithelium during embryological development [49]. In this case, associated chronic inflammation of the biliary system would initiate intestinal metaplasia, predisposing to the development of neuroendocrine tumours [50].

Our search found 69 cases of PHCT reported in the literature [7-48]. Carcinoid syndrome is present in fewer cases when compared to liver metastatic carcinoid tumours [11]. It is also noteworthy that the major cause of 'primary' hepatic carcinoids are often cases of missed primaries. This is supported by the relative rarity of carcinoid syndrome, which is suggestive of a hind-gut origin. A proposed algorithm for diagnosis uses computed to-

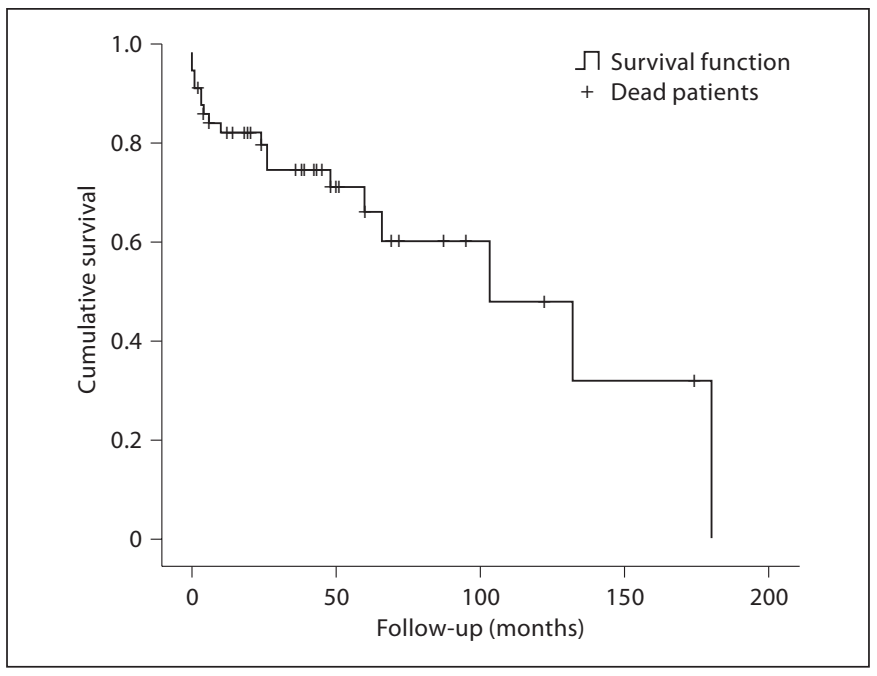

Fig. 1. Kaplan-Meier curve of patient survival.

mography (CT) and magnetic resonance imaging (MRI) initially, followed by octreoscan, upper and lower gastrointestinal endoscopy and explorative laparotomy for the exclusion of an extra-hepatic carcinoid tumour [7]. Even when all of these elements point towards a case of PHCT, a protracted long-term follow-up is necessary in order to exclude an underlying extrahepatic primary tumour that could have been mistaken by the diagnostic tools available [12].

Failure to locate primary extrahepatic carcinoids is common, occurring in some $16 \%$ of cases [51, 52]. The radiological appearance of the hepatic mass can be helpful, as PHCT are typically solitary and centrally located, while a multi-nodular appearance is more suggestive of metastases [7]. Other diagnostic tools that may be considered are elevated blood chromogranin A, elevated urinary 24-hour 5-hydroxyindoleacetic acid [53] and, in cases of previous appendectomy, to review the appendix histology [54]. In spite of implementing this armoury of diagnostic tools, extrahepatic carcinoids can sometimes be diagnosed years after the initial treatment highlighting the shortcomings of the available techniques for the diagnosis of PHCT [55]. Therefore, it is necessary to reevaluate those patients that have been operated upon with clinical and biochemical investigations, a CT scan of the chest, abdomen and pelvis and octreoscan at long follow-ups [7].

Surgical resection remains the mainstay of PHCT treatment. The same criteria for eligibility are applied in PHCT as those adopted in cases of more common liver tumours. With this treatment, good long-term prognoses 
have been described [7]. LT has also been successfully reported in a small number of unresectable cases [7-8]. This is a well-recognized option in specific patients affected by neuroendocrine tumours that have metastasised to the liver when the mass is not resectable; it is associated with life-threatening hormone secretion (e.g. insulin or histamine) or does not respond to other procedures (i.e. local ablation or hepatic artery embolization) [56-58]. Arnold et al. [8] reported the case of a 35-yearold woman that, 4 years after the diagnosis of PHCT, presented with increasing lethargy, abdominal discomfort, profuse sweating and weight loss. Intraoperatively, large tumour masses were found in both lobes and a tiny cancerous deposit in one hilar lymph node. Thirty-eight months from the post-transplant, the patient was alive and free from disease [8]. In a further series of 8 PHCT patients, Fenwick et al. [7] reported the use of LT in 2 cases. In the first case, a 40-year-old woman presented with abdominal distension and pain. CT and MRI demonstrated a $12-\mathrm{cm}$ centrally located liver tumour. Intraoperative ultrasonography showed that hepatic veins were extensively involved with the tumour. The patient was disease free 8 years after the LT, with no evidence of tumour on serial CT and somatostatin scan assessments. The second case was a 50 -year-old man, whose MRI scan demonstrated a $12-\mathrm{cm}$ tumour involving both the left and right branches of the hepatic portal vein, the hepatic artery and the hepatic ducts, but with no evidence of extrahepatic disease. Laparotomy revealed a bilobar unresectable tumour. Forty-five months after LT, the patient was disease free [7].
All reports of LT for the treatment of PHCT showed no disease recurrence at 38, 45 and 95 months post-operatively $[7,8]$, but follow-up is still inadequate to suggest a definitive role in the management of unresectable primary carcinoids. In fact, the potential for an undetected extrahepatic primary carcinoid being present leaves the adoption of LT open to debate, requiring further investigation to assess potential applications in this setting. For this reason, to date the mainstay of treatment for PHCT remains liver resection and appropriate prospective studies with long follow-ups should allow for improved evaluation of the merits of LT as an option for patients with unresectable hepatic masses.

\section{Conclusions}

Primary carcinoids of the liver are a rare and interesting entity that if correctly diagnosed and treated can achieve good long-term results. The major diagnostic pitfall resides in our current inability to accurately exclude other primary locations, including the appendix and small bowel. The development of novel diagnostic tools or improving the accuracy of current methods may enhance our ability to identify other primary locations. Once the surgeon is confident that the primary carcinoid is of hepatic origin, best practice remains surgical resection. However, in the light of positive outcomes for patients who received an LT, future large and prospective studies should evaluate this as an option for unresectable cases.

\section{References}

1 Caplin ME, Buscombe JR, Hilson AJ, Jones $\mathrm{AL}$, Watkinson AF, Burroughs AK: Carcinoid tumor. Lancet 1998;352:799-805.

2 Modlin IM, Sandor A: An analysis of 8,305 cases of carcinoid tumors. Cancer 1997;79: 813-829.

-3 Yamashita Y, Takahashi M, Tsuji A, Korogi Y, Uozumi H, Kimura Y: Primary carcinoid tumor of the liver: a case report. J Comput Tomogr 1986;10:313-317.

4 Zhang A, Xiang J, Zhang M, Zheng S: Primary hepatic carcinoid tumours: clinical features with an emphasis on carcinoid syndrome and recurrence. J Int Med Res 2008; $36: 848-859$.

5 Nikfarjam M, Muralidharan V, Christophi C: Primary hepatic carcinoid tumours. HPB (Oxford) 2004;6:13-17.
6 Soga J: Primary hepatic endocrinomas (carcinoids and variant neoplasms). A statistical evaluation of 126 reported cases. J Exp Clin Cancer Res 2002;21:457-468.

7 Fenwick SW, Wyatt JI, Toogood GJ, Lodge JP: Hepatic resection and transplantation for primary carcinoid tumors of the liver. Ann Surg 2004;239:210-219.

-8 Arnold JC, O'Grady JG, Bird GL, Calne RY, Williams R: Liver transplantation for primary and secondary hepatic apudomas. $\mathrm{Br} \mathrm{J}$ Surg 1989;76:248-249.

$\checkmark 9$ Hsueh C, Tan XD, Gonzalez-Crussi F: Primary hepatic neuroendocrine carcinoma in a child. Morphologic, immunocytochemical, and molecular biologic studies. Cancer 1993; 71:2660-2665.

10 Brown WM 3rd, Henderson JM, Kennedy JC: Carcinoid tumor of the bile duct: a case report and literature review. Am Surg 1990; 56:343-346.
11 Ruckert RI, Ruckert JC, Dorffel Y, Rudolph B, Muller JM: Primary hepatic neuroendocrine tumor: successful hepatectomy in two cases and review of the literature. Digestion 1999;60:110-116.

12 Iimuro Y, Deguchi Y, Ueda Y, Tanaka A, Iwasa Y, Ishihara M, Mizuta K, Yamamoto Y, Ikai I, Shimahara Y, Yamaoka Y: Primary hepatic carcinoid tumor with metachronous lymph node metastasis after long-term follow up. J Gastroenterol Hepatol 2002;17: 1119-1124.

13 Arnold JC, O'Grady JG, Bird GL, Calne RY, Williams R: Liver transplantation for primary and secondary hepatic apudomas. Br J Surg 1989;76:248-249.

14 Primack A, Wilson J, O’Connor GT, Engelman K, Hull E, Canellos GP: Hepatocellular carcinoma with carcinoid syndrome. Cancer 1971;27:1182-1189. 
15 Ali M, Fayemi AO, Braun EV: Malignant apudoma of the liver with symptomatic intractable hypoglycemia. Cancer 1978;42: 686-692.

16 Walter JF, Appelman HD, Reuter SR: Angiographic and pathological features of probable primary carcinoid-like hepatic tumors. Gastrointest Radiol 1978;3:397-400.

17 Warner TF, Seo IS, Madura JA, Polak JM, Pearse AG: Pancreatic-polypeptide-producing apudoma of the liver. Cancer 1980;46: 1146-1151.

18 Gould VE, Banner BF, Baerwaldt M: Neuroendocrine neoplasms in unusual primary sites. Diagn Histopathol 1981;4:263-277.

19 Barsky SH, Linnoila I, Triche TJ, Costa J: Hepatocarcinoma with carcinoid features. Hum Pathol 1984;15:892-894.

-20 Norgaard T, Bardram L: Endocrine liver tumor differential diagnosis from hepatocellular carcinoma. Histopathology 1985;9:777781.

21 Smith AL, Auldist AW: Successful surgical resection of an hepatic gastrinoma in a child. J Pediatr Gastroenterol Nutr 1984;3:801804.

22 Xi YP, Yu JY: Primary neuroendocrine carcinoma of the liver. Ultrastruct Pathol 1986; 10:331-336.

23 Miura K, Shirasawa H: Primary carcinoid tumor of the liver. Am J Clin Pathol 1988;89: 561-564.

-24 Andreola S, Lombardi L, Audisio RA, Mazzaferro V, Koukouras D, Doci R, Gennari L, Makowka L, Starzl TE, van Thiel DH: A clinicopathologic study of primary hepatic carcinoid tumors. Cancer 1990;65:1211-1218.

25 Sioutos N, Virta S, Kessimian N: Primary hepatic carcinoid tumor. An electron microscopic and immunohistochemical study. Am J Clin Pathol 1991;95:172-175.

-26 Aoki K, Sakamoto M, Mukai K, Kosuge T, Takayama T, Hiroshashi S: Signet-ring cell carcinoid: a primary hepatic carcinoid tumor with cytoplasmatic inclusion comprising of aggregates of keratin. Jpn J Clin Oncol 1992;22:54-59.

- 27 Inoue Y, Nakamura H, Mizumoto S, Mori H, Yamasaki K: Primary hepatic carcinoid with production of gastrin: a case report. Radiat Med 1993;11:102-106.

28 Imaoka I, Sugimura K, Tamura K: Case report: MR imagining of a carcinoid tumor of the liver. Clin Radiol 1993;47:287-289.

- 29 Yasoshima H, Uematsu K, Sakurai K, Ueno Y, Hori K, Kanazawa N, Tanaka T, Yamanaka N, Okamoto E: Primary hepatic carcinoid tumor. Acta Pathol Jpn 1993;43:783-789.

-30 Artopoulos JG, Destuni C: Primary mixed hepatocellular carcinoma with carcinoid characteristics. A case report. Hepatogastroenterology 1994;41:442-444.

- 31 Moriura S, Ikeda S, Hirai M, Naiki K, Fujioka T, Yokochi K, Gotou S: Hepatic gastrinoma. Cancer 1993;72:1547-1550.

- 32 Krishnamurthy SC, Dutta V, Pai SA, Kane SV, Jagannath P, Desouza LJ, Deshpande R, Desai PB: Primary carcinoid tumor of the liver: report of four resected cases including one with gastrin production. J Surg Oncol 1996;62:218-221.

33 Oh YH, Kang GH, Kim OJ: Primary hepatic carcinoid tumor with paranuclear clear zone: a case report. J Kor Med Sci 1998;13: 317-320.

34 Sano K, Kosuge T, Yamamoto J, Shimada K, Takayama T, Yamasaki S, Makuuchi M: Primary hepatic carcinoid tumor confirmed with a long-term follow-up after resection. Hepatogastroenterology 1999;46:2547-2550.

35 Fujino K, Koito K, Sano S, Takahara T, Nakamura E, Morisaki Y, Furuya T, Torigoe T, Ishii Y: A primary hepatic carcinoid tumor: evaluation by computed tomography and magnetic resonance imagining. Radiat Med 1998; 16:371-373.

36 Asakawa T, Tomioka T, Abe K, Yamaguchi T, Tsunoda T, Kanematsu T: Primary hepatic carcinoid tumor. J Gastroenterol 1999;34: 123-127.

37 Nemes B, Podder H, Jaray J, Dabasi G, Schaff Z, Sotonyi P Jr, Perner F: Primary hepatic carcinoid tumor in renal transplant patient. Pathol Oncol Res 1999;5:67-69.

38 Mizuno Y, Ohkohchi N, Fujimori K, Doi H, Orii T, Asakura T, Kimura N, Pilichowska M, Inomata M, Satomi S: Primary hepatic carcinoid tumors: a case report. Hepatogastroenterology 2000;47:528-530.

39 Kim SR, Imoto S, Maekawa Y, Matsuoka T, Hayashi Y, Ando K, Mita K, Shintani S, Kim HB, Ku K, Koterazawa T, Fukuda K, Yano Y, Nakaji M, Ikawa H, Ninomiya T, Kudo M, Kim KI, Hirai M: CEA producing primary hepatic carcinoid. Hepatol Res 2002;22:313321.

40 Iwao M, Nakamuta M, Enjoji M, Kubo H, Fukutomi T, Tanabe Y, Nishi H, Taguchi KI, Kotoh K, Nawata H: Primary hepatic carcinoid tumor: case report and review of 53 cases. Med Sci Monit 2001;7:746-750.

41 Hasuike Y, Takeda Y, Ueda S, Tujinaka T, Yoshida K: A case of primary hepatic carcinoid tumor with lymph node metastasis - treatment of hepatic arterial infusion to post-reoperative liver and radiation to metastasis of para-aortic lymph nodes. Jpn J Cancer Chemother (Gan To Kagaku Ryoho) 2002;29: 2433-2436.

-42 Ishizu A, Yokoyama K, Yoshiki T: Primary neuroendocrine carcinoma of the liver diagnosed at autopsy. J Gastroenterol Hepatol 2003; 18:1002-1004.

-43 Knox CD, Anderson CD, Lamps LW, Adkins $\mathrm{RB}$, Pinson CW: Long-term survival after resection for primary hepatic carcinoid tumor. Ann Surg Oncol 2003;10:1171-1175.

-44 Kaya G, Pasche C, Osterheld MC, Chaubert P, Fontolliet C: Primary neuroendocrine carcinoma of the liver: an autopsy case. Pathol Int 2001;51:874-878.

45 Tohyama T, Matsui K, Kitagawa K: Primary hepatic carcinoid tumor with carcinoid syndrome and carcinoid heart disease: a case report of a patient on long-term follow-up. Int Med 2005;44:958-962.
46 Komatsuda T, Ishida H, Furukawa K, Takaharu M, Heianna J: Primary carcinoid tumor of the liver: report of a case with an emphasis on contrast-enhanced ultrasonographic findings. J Clin Ultrasound 2005;33:302304.

- 47 Kohashi T, Itamoto T, Katayama K, Nakahara $\mathrm{H}$, Onoe $\mathrm{T}$, Matsugu $\mathrm{Y}$, Nakatsuka H, Arataki K, Shimamoto F, Asahara T: Primary hepatic carcinoid tumor (a case report). Hepatogastroenterology 2005; 52: 1218-1220.

48 Abdel Wahab M, Fathy O, Elghwalby N, Sul$\tan$ A, Mostafa M, El Baz M, Elsaadany M, Elshobary M, Ezzat F: Primary hepatic carcinoid tumor: one Egyptian centre experience. Hepatogastroenterology 2006;53:3338.

49 Alpert LI, Zak FG, Wethamer S, Bochetto JF: Cholangiocarcinoma: a clinicopathologic study of five case with ultrastructural observations. Hum Pathol 1974;5:709-728.

50 Brown WM 3rd, Henderson JM, Kennedy JC: Carcinoid tumor of the bile duct: a case report and literature review. Am Surg 1990; 56:343-346.

51 Le Treut YP, Grégoire E, Belghiti J, Boillot O, Soubrane O, Mantion G, et al: Predictors of long-term survival after liver transplantation for metastatic endocrine tumors: an 85case French multicentric report. Am J Transplant 2008;8:1205-1213.

52 Chamberlain RS, Canes D, Brown KT, Saltz $\mathrm{L}$, Jarnagin W, Fong Y, et al: Hepatic neuroendocrine metastases: does intervention alter outcomes? J Am Coll Surg 2000;190:432445.

53 Bajetta E, Procopio G, Buzzoni R, Catena L, Ferrari L, Del Vecchio M: Advances in diagnosis and therapy of neuroendocrine tumors. Expert Rev Anticancer Ther 2001;1: 371-381.

54 Kulke MH, Mayer RJ: Carcinoid tumors. N Engl J Med. 1999;340:858-867.

- 55 Rosenau J, Bahr MJ, von Wasielewski R, Mengel M, Schmidt HH, Nashan B, et al: $\mathrm{Ki} 67, \mathrm{E}$-cadherin, and p53 as prognostic indicators of long-term outcome after liver transplantation for metastatic neuroendocrine tumors. Transplantation 2002;73:386394

56 Le Treut YP, Delperro JR, Dousset B, Cherqui D, Segol P, Mantion G, Hannoun L, Benhamou G, Lanunois B, Boillot O, Domergue J, Bismuth H: Results of liver transplantation in the treatment of metastatic neuroendocrine tumors. Ann Surg 1997;225:355-364.

57 Lehnert T: Liver transplantation for metastatic neuroendocrine carcinoma: an analysis of 103 patients. Transplantation 1998;66: 1307-1312.

58 Olausson M, Friman S, Cahlin C, Nilson O, Jansson S, Wangberg B, Ahlman H: Indications and results of liver transplantation in patients with neuroendocrine liver tumors. World J Surg 2002;26:998-1004. 